\title{
A PRACTICAL TOOLKIT OF STRATEGIES FOR BUILDING RESEARCH CAPACITY IN ALLIED HEALTH
}

\author{
Janine Matus', Rachel Wenke 1,2, Sharon Mickan 1,2 \\ 1. Gold Coast Health - Allied Health Southport, Queensland, Australia \\ 2. Griffith University, Gold Coast, Queensland, Australia
}

Correspondence: matusjanine@gmail.com

\section{ABSTRACT}

\section{OBJECTIVES}

The objectives of this project were firstly to develop a practical toolkit of evidence-informed strategies for building research capacity in allied health, and secondly to disseminate and apply this toolkit to inform tailored research capacity building plans for allied health teams.

\section{DESIGN:}

This project used a plan, do, study, act (PDSA) quality improvement methodology to develop, disseminate and apply a toolkit which was based on the results of a recent systematic review of allied health research capacity building frameworks and a narrative review of other interventions and theoretical recommendations.

\section{SETTING}

Eight allied health professional teams in a publicly funded tertiary health service were supported to develop tailored research capacity building plans based on their specific needs, goals and context.

\section{MAIN}

outcome measures: The outcomes of this project were evaluated using process measures including whether a research capacity building plan was developed and to what extent short-term goals were achieved within three months.

\section{RESULTS}

A practical toolkit was developed which consolidates existing evidence-informed strategies and organises these around three components including 'supporting clinicians in research', 'working together' and 'valuing research for excellence' and 17 sub-components. Several barriers and facilitators to applying the toolkit to teams were identified and this paper suggests some recommendations and future directions for addressing these.

\section{CONCLUSIONS}

This toolkit may be a useful resource to inform the development of team-based research capacity building plans for allied health. The application of the toolkit may be enhanced by a need's assessment and facilitation from a researcher.

\section{KEYWORDS}

allied health, research capacity building, research culture

\section{INTRODUCTION}

Building the research capacity and capability of Australian health services is recognised as a priority because of the benefits this brings for individuals, the nation and the economy [1]. Research capacity building is "a process of developing sustainable abilities and skills enabling individuals and organisations to perform high quality research" [2]. The goal of research capacity building is to complement health professionals' existing clinical expertise with research skills [3].

Allied health professionals represent the third largest clinical workforce in Australia and include physiotherapists, occupational therapists, dietitians, speech pathologists, social workers, psychologists, pharmacists and podiatrists. 
Allied health professionals who are engaged in performing research tend to have more positive perceptions of research, be better at applying research evidence to inform their practice and enjoy greater job satisfaction [36]. Research also provides a means for allied health professionals to evaluate the quality and efficiency of their services $[3,6]$, contribute to a wider base of evidence to inform service planning and delivery, advance their profession's base of knowledge and influence funding bodies $[3,5,7]$.

Although Australian allied health professionals have reported that they are interested in conducting research [8-10], their research culture and engagement remains relatively limited [11, 12] due to a number of barriers including a lack of time, other work roles taking priority and a lack of research skills [12, 13]. The most common motivators for doing research are to address identified problems in practice, provide the best possible care for clients, build the evidence base to inform service delivery, improve job satisfaction and enhance career opportunities $[5,6,12,13]$. Based on a recent needs assessment conducted in our health service in $2017,62 \%$ of responding allied health professionals were engaged in research activity over the preceding 20 month period, with the most commonly undertaken activities being collecting data, completing a literature review, and writing an ethics application [14]. Overall, participants self-reported moderate to high levels of skill and success in undertaking research, although there was variability between professional groups. The most common barriers and motivators to engaging in research were comparable to those reported in the literature.

In efforts to address these barriers and motivators, several allied health research capacity building interventions have been implemented in Australia [4, 9, 10, 15-19] and internationally $[20,21]$. Additionally, numerous strategies have been recommended based on evaluations of the needs, interests and experiences of allied health professionals $[3,5,6,8,12,13,22]$ and mixed groups of health professionals $[7,23,24]$. Commonly recommended strategies include protected time, funding, support from managers, mentoring, partnerships and dedicated research facilitators $[8,12,22]$.

Several existing frameworks outline potential strategies for allied health research capacity building $[4,7,21]$. Slade ef al [25] recently conducted a rapid review of published theories and frameworks for embedding research in the allied health clinical sector [25]. The recommendations from this review were aimed at informing a future policy framework for embedding allied health research into routine clinical practice across public and private healthcare systems, rather than having a practical focus for clinicians and managers. Another recent systematic review by Matus et al [26] synthesised existing research capacity building frameworks relevant for allied health professionals. Three interconnected and interdependent themes were commonly found from the frameworks including 'supporting clinicians in research', 'working together' and 'valuing research for excellence'. These three themes, 17 subthemes and supporting evidence-informed strategies form the basis of a succinct and integrated new allied health research capacity building framework [26]. However, this framework is not yet in a practical format for implementation by clinicians and managers.

The objectives guiding this service improvement project were firstly to develop a practical toolkit of evidenceinformed research capacity building strategies for allied health; and secondly to disseminate and apply this toolkit to inform the development of tailored research capacity building plans for allied health teams based on their specific needs and context. To exemplify the second objective, we will describe a short-term case study of how one allied health team was supported to develop a tailored research capacity building plan using the toolkit.

\section{METHODS}

This project used a quality improvement methodology based on the plan, do, study, act (PDSA) cycle, with two phases to address the project's objectives: 1 . development of the toolkit and 2. dissemination and application of the toolkit. Ethical approval was sought however the project was judged to be service improvement and exempt from ethical review. HREC/17/QGC/360.

\section{SETTING}

The project was undertaken in a large publicly funded Australian tertiary health service which includes two hospital facilities (750 and 364 beds) in addition to outpatient and community-based services. This health service employs approximately 900 allied health professionals including dietitians, radiographers, sonographers, occupational therapists, pharmacists, physiotherapists, psychologists, social workers and speech pathologists. Since 2014, the health service has significantly 
invested in building allied health research activity by appointing a Professor of Allied Health and three Allied Health Research Fellows, who together have implemented and evaluated a range of education, mentoring, and funding initiatives $[27,28]$.

\section{Phase 1: Development of the toolkit}

The toolkit was based on a recently developed allied health research capacity building framework which was informed by the results of a systematic review [26], as described in the introduction. The evidence-informed strategies included in this framework were further consolidated and supplemented with other published interventions and theoretical recommendations $[4,7,15$, $17,21,22]$. These articles were identified using the same search strategy as the systematic review, but were not included in the systematic review because they comprised single strategies and interventions rather than a suite of different approaches [26]. The authors consulted with the allied health research fellows working in this health service to achieve a consensus regarding the strategies to be included in the toolkit and to refine the content of the toolkit prior to its dissemination.

\section{Phase 2: Dissemination and application of the toolkit}

\section{Participants and procedures}

The toolkit was first presented at an allied health leadership and governance meeting which was attended by the senior managers of each allied health professional group in November 2017. To support the application of the toolkit, profession-specific needs assessments were undertaken during April 2017 as part of a larger project [14]. These needs assessments included baseline measures of research skills, successes, barriers and motivators using the Research Capacity and Culture (RCC) tool [2] and an audit of research activity conducted by each group.

Senior managers of the eight largest allied health professional groups in our health service were invited to participate in meetings with JM and SM to review the results of their needs assessment and discuss how the toolkit could be used to inform tailored research capacity building plans for their teams. All managers were encouraged to identify suitable strategies which were relevant to their needs, goals and context, including a mix of strategies from each of the three components of the toolkit. Senior managers and their teams were additionally invited to participate in a threemonth project to develop and implement a more detailed research capacity building plan with support from a project officer (JM).

The outcomes of this project were evaluated using process measures, including whether a research capacity building plan was developed and to what extent short-term goals were achieved within three months. These process measures were collected by project officer JM through consultation with the managers and research team. They were selected to monitor progress towards achieving longer term outcomes including increased research engagement and outputs. Subjective barriers and facilitators to the process of developing and implementing the plans were recorded using reflective notes and meeting minutes.

\section{RESULTS}

\section{Phase 1: Development of the toolkit}

A practical allied health research capacity building toolkit was developed (see Appendix 1). This toolkit consolidates evidence-informed strategies extracted from existing frameworks [4, 15, 17, 20-22] and other interventions and theoretical recommendations $[3,5-10,12,13,18,23,24]$. These strategies are organised around three components including 'supporting clinicians in research', 'working together' and 'valuing research for excellence' and 17 sub-components (see Figure 1). Some examples of subcomponents include providing opportunities to get involved in research, encouraging a team-based approach; prioritising research that is 'close to practice' and integrating local research findings back into practice. 


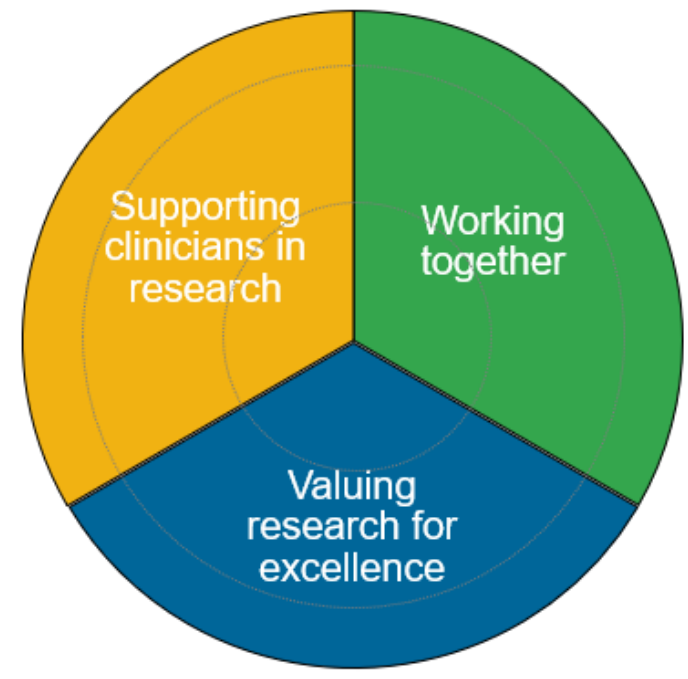

\begin{tabular}{|c|c|c|}
\hline $\begin{array}{l}\text { Supporting } \\
\text { clinicians in research }\end{array}$ & Working together & $\begin{array}{l}\text { Valuing research } \\
\text { for excellence }\end{array}$ \\
\hline $\begin{array}{l}\text { - Opportunities to get involved } \\
\text { - Research friendly } \\
\text { workplace } \\
\text { - Mentoring/supervision } \\
\text { - Skill mix of teams } \\
\text { - Education and training } \\
\text { - Post-graduate study } \\
\text { - Protected time and funding } \\
\text { - Reward and recognition } \\
\text { - Access to resources }\end{array}$ & $\begin{array}{l}\text { - Collaborations and } \\
\text { partnerships } \\
\text { - Shared purpose and drivers } \\
\text { - Coordinated approach } \\
\text { including team projects } \\
\text { - Shared expertise }\end{array}$ & $\begin{array}{l}\text { - Visible support for research } \\
\text { - Research as core business } \\
\text { - Prioritise research that is } \\
\text { 'close to practice' } \\
\text { - Integrate local research } \\
\text { findings back into practice }\end{array}$ \\
\hline
\end{tabular}

Phase 2: Dissemination and application of the toolkit All eight senior managers participated in at least one meeting to review the results of their needs assessment and discuss how the toolkit could be applied to inform a tailored research capacity building plan for their team. Although some of the professional groups had previously accessed support from allied health research fellows or university colleagues, they had not utilised the new research capacity toolkit prior to participating in this project. Teams 1-6 attended a single meeting and generated a list of strategies to be implemented. Teams 7 and 8 requested support to develop a more detailed research capacity building plan consisting of long and short-term goals. Team
8 also requested support to begin implementing their plan. In line with Roger's Diffusion of Innovation theory, Team 8 was selected because they demonstrated the greatest level of motivation and as such were deemed most likely to become early adopters of change within the organisation [29].

Over a three-month period, project officer JM worked closely with a group of five senior and middle managers and ten research-interested clinicians from Team 8 to prioritise and action a selection of strategies relating to their short-term goals. Seven formal face-to-face meetings were organised and chaired by the project officer in the team's 
workplace. During these meetings, the project officer presented data from the need's assessment, suggested potentially relevant strategies from the toolkit and facilitated discussion. The meeting agendas included achieving agreement regarding the team's long- and short-term research capacity building goals, developing tailored strategies, allocating roles and responsibilities within the team and reviewing progress. Between meetings, the project officer also supported individual team members to action their allocated tasks. The final list of strategies and summary of progress after three months are outlined in Table 1. Most of the strategies addressed the component 'supporting clinicians in research'. At the end of the three-month period, over half of the strategies in the plan had been achieved, while the others remained in progress. The strategy 'negotiating shared research priorities and projects' had not commenced because the team decided to prioritise identifying their own strategic drivers first, to ensure that future research collaborations will be relevant to their service needs.

\section{TABLE 1: TEAM 8'S RESEARCH CAPACITY BUILDING PLAN - STRATEGIES RELATING TO SHORT-TERM GOALS}

\begin{tabular}{|c|c|}
\hline STRATEGY & $\begin{array}{l}\text { PROGRESS AFTER } 3 \\
\text { MONTHS }\end{array}$ \\
\hline \multicolumn{2}{|l|}{ Supporting clinicians in research } \\
\hline Establish a peer support group for research. & Achieved \\
\hline $\begin{array}{l}\text { Create opportunities for staff to participate in small and/or team- } \\
\text { based research projects. }\end{array}$ & In progress \\
\hline Consistently implement journal club across teams. & In progress \\
\hline Identify potential research mentors (internal and external). & In progress \\
\hline Develop a register of current and future research projects. & Achieved \\
\hline Develop a directory of local research resources and supports. & Achieved \\
\hline Develop a guideline for 'how to do research' in local context. & Achieved \\
\hline \multicolumn{2}{|l|}{ Working together } \\
\hline $\begin{array}{l}\text { Negotiate shared research priorities and projects with academic } \\
\text { partners at a co-located university. }\end{array}$ & Not commenced \\
\hline \multicolumn{2}{|l|}{ Valuing research for excellence } \\
\hline Identify strategic drivers for research. & Achieved \\
\hline Prioritise 1-3 topics/projects which align to strategic drivers. & In progress \\
\hline $\begin{array}{l}\text { Establish a process for approving staff to conduct research projects, } \\
\text { secondments and HDR. }\end{array}$ & Achieved \\
\hline Communicate senior managers' commitment to research. & Achieved \\
\hline $\begin{array}{l}\text { Clarify expectations regarding research engagement of junior, } \\
\text { senior and management staff. }\end{array}$ & In progress \\
\hline Include research activities in staff role descriptions. & In progress \\
\hline
\end{tabular}




\section{Barriers and facilitators}

Several barriers and facilitators to applying the toolkit were identified based on reflections by the project officer (JM).

Barriers included a lack of time to dedicate to the process of developing and implementing research plans due to organisational pressures to maximise clinical service provision. Some senior managers perceived a lack of incentives to prioritise research capacity building over other competing operational and service delivery demands. Several managers and clinicians reported a low level of confidence to lead or facilitate research within their teams. Other barriers included selecting too many strategies at once, which became overwhelming, and not knowing how to effectively implement these strategies. Facilitators included building on existing motivators, linking research engagement goals to strategic plans and key performance indicators, making clear plans for how to implement and evaluate the success of prioritised strategies, and actively involving the whole team in the process of developing their research capacity building plan, including managers and clinicians. Indeed, the formation of a research committee by Team 8 allowed for a number of strategies to be actioned within the team and allowed for greater ownership of the strategies.

\section{DISCUSSION}

This quality improvement project developed a practical toolkit of evidence-informed research capacity building strategies. We described the dissemination and application of the toolkit within eight allied health professional teams, including a case study of one team who used the tool to develop and implement a tailored research capacity building plan.

To our knowledge, this is the first project which has described a practical toolkit to promote research capacity building in allied health teams. Two previous studies found that team-based interventions may be effective in terms of improving participants' research capabilities, confidence and outputs, developing linkages and collaborations, and increasing perceived research capacity and culture at the level of individuals, teams and the organisation [15, 20]. Whereas these previous studies implemented standardised interventions, the current study focussed on facilitating teams to develop locally tailored plans consisting of a combination of strategies which were relevant to their goals, needs and context. Given the multiple competing demands operating in health services, this toolkit may assist managers to prioritise the investment of limited time and resources for best outcomes in terms of maximising allied health research engagement. We found that a facilitator (in our case a project officer) was able to guide managers to select, tailor and implement appropriate strategies for their team, from the toolkit.

\section{LIMITATIONS AND FUTURE DIRECTIONS}

A limitation of this study is that it was descriptive summary in one health service. While the present study highlights some potential benefits, further research is indicated to evaluate the development and implementation of tailored research capacity building plans based on the toolkit. A mixed methods approach would be useful to evaluate a range of potential short, medium, and long-term outcomes including improvements in allied health professionals' knowledge, skills, confidence and attitudes towards research; changes in the proportion of staff who are using, participating in and leading research; increases in traditional research outputs such as peer-reviewed publications, conference presentations and competitive grant funding; the establishment of additional research collaborations and partnerships; changes in clinical practice and patient outcomes Implementing research plans within a team requires some kind of behaviour change by both clinicians and their managers, and for such a change to occur, individuals require adequate opportunity, capability and motivation [30]. While this toolkit provides information about "what" strategies to implement, which may guide planning and evaluation, it does not offer guidance for "how" to implement these strategies or "how" to facilitate behaviour change.

The current study found that both managers' and clinicians' support and active involvement in the process of developing goals and plans for research capacity building is important. This finding confirms and builds on previous literature which suggested that senior managers' support for research is needed across the whole organisation [22]. Future research may wish to investigate how a knowledge translation approach could support behaviour change by evaluating the barriers and facilitators more systematically and from different sources. This could then inform the development of targeted behaviour change interventions such as education, training, modelling, incentivisation and environmental restructuring [30]. 
While other research capacity building approaches have been focussed at the level of individuals [10, 28], organisations $[4,16,17]$ or policy $[9,21,25]$, this project was targeted at the level of teams. Another suggested future direction for research is to apply the toolkit at both organisation and team levels, in addition to supporting individual research-interested clinicians, as part of the recommended 'whole of system' approach.

\section{PRACTICAL RECOMMENDATIONS}

In the present study, application of the toolkit was informed by the results of a needs assessment which identified the unique strengths, areas for development, barriers and motivators operating in each team. A rigorous needs assessment is helpful for measuring baseline research capacity and culture, thus ensuring that strategies address areas that require attention and providing a means of evaluating change over time. Previous research suggests it may be more useful to focus on enhancing motivators rather than removing barriers [11]. Thus, it may be advantageous to prioritise implementing research capacity building strategies which target teams' existing motivators for conducting research, as identified through a needs assessment.

While all health professionals should be using research evidence to inform their practice, not all are expected to undertake projects that will generate new research evidence [31]. It has previously been recognised that research capacity building initiatives need to be flexible to accommodate different contexts, professional backgrounds and levels of interest and experience in using and generating research [32]. Indeed, a recent Australian study of 95 AHPs from eight professional teams suggested that a one size fits all approach is unlikely to be effective and that research capacity building initiatives should target professional teams separately and according to their specific needs [11]. Therefore, it is recommended that a facilitator with research experience is available to support the process of developing tailored research capacity building plans which take into consideration the goals, interests and developmental level of each team.

\section{CONCLUSIONS}

This practical toolkit of strategies to build allied health research capacity may be a useful resource for informing allied health research capacity building plans. The application of the toolkit may be enhanced through the use of a needs assessment and local facilitation.
Consideration should be given to systematically evaluating and addressing barriers and facilitators to applying the toolkit, possibly as part of a knowledge translation approach.

\section{References}

1. McKeon S, Alexander E, Brodaty H, Ferris B, Frazer I, Little M. Strategic review of health and medical research in Australia. Canberra: Commonwealth of Australia; 2013; 1-304.

2. Holden L, Pager S, Golenko X, Ware RS. Validation of the research capacity and culture (RCC) tool: measuring RCC at individual, team and organisation levels. Aust J Primary Health 2012; 18(1): 62-7.

3. Pickstone C, Nancarrow S, Cooke J, Vernon W, Mountain G, Boyce R. Building research capacity in the allied health professions. Evid Policy 2008; 4(1): 53 68.

4. Hulcombe J, Sturgess J, Souvlis T, Fitzgerald C. An approach to building research capacity for health practitioners in a public health environment: an organisational perspective. Aust Health Rev 2014; 38(3): 252-8.

5. Pager S, Holden L, Golenko X. Motivators, enablers, and barriers to building allied health research capacity. J Multidiscip Healthc 2012; 5: 53-9.

6. Skinner EH, Williams CM, Haines TP. Embedding research culture and productivity in hospital physiotherapy departments: challenges and opportunities. Aust Health Rev 2015; 39(3): 312-4.

7. Cooke J. A framework to evaluate research capacity building in health care. BMC Fam Pract 2005; 6(44): 1-11.

8. Harvey D, Plummer D, Nielsen I, Adams R, Pain T. Becoming a clinician researcher in allied health. Aust Health Rev 2016; 40(5): 562-9.

9. Ried K, Farmer EA, Weston KM. Bursaries, writing grants and fellowships: a strategy to develop research capacity in primary health care. BMC Fam Pract 2007; 8(1): 19 .

10. Harding KE, Stephens D, Taylor NF, Chu E, Wilby A. Development and evaluation of an allied health research training scheme. J Allied Health 2010; 39(4): 143-8.

11. Wenke RJ, Mickan S, Bisset L. A cross sectional observational study of research activity of allied 
health teams: is there a link with self-reported success, motivators and barriers to undertaking research? BMC Health Serv Res 2017; 17(1): 114.

12. Borkowski D, McKinstry C, Cotchett M, Williams C, Haines T. Research culture in allied health: a systematic review. Aust J Prim Health 2016; 22(4): 294303.

13. Alison JA, Zafiropoulos B, Heard R. Key factors influencing allied health research capacity in a large Australian metropolitan health district. J Multidiscip Healthc 2017; 10: 277-91.

14. Matus J, Wenke R, Hughes I, Mickan S. Evaluation of the research capacity and culture of allied health professionals in a large regional public health service. J Multidiscip Healthc 2019; 12: 83-96.

15. Holden L, Pager S, Golenko X, Ware RS, Weare R. Evaluating a team-based approach to research capacity building using a matched-pairs study design. BMC Fam Pract 2012; 13(1): 16.

16. Murphy K, Stockton D, Kolbe A, Hulme-Chambers A, Smythe G. Building research capacity in a regional Australian health service: a management strategy analysis. Asia Pacific Journal of Health Management 2015; 10(1): 14.

17. Bamberg J, Perlesz A, McKenzie P, Read S. Utilising implementation science in building research and evaluation capacity in community health. Aust J Prim Health 2010; 16(4): 276-83.

18. Joubert L, Hocking A. Academic practitioner partnerships: a model for collaborative practice research in social work. Australian Social Work 2015; 68(3): 352-63.

19. Wenke RJ, Ward EC, Hickman I, Hulcombe J, Phillips R, Mickan S. Allied health research positions: a qualitative evaluation of their impact. Health Res Policy Syst 2017; 15: 6.

20. Cooke J, Nancarrow S, Dyas J, Williams M. An evaluation of the 'designated research team' approach to building research capacity in primary care. BMC Fam Pract 2008; 9: 37.

21. Whitworth A, Haining S, Stringer H. Enhancing research capacity across healthcare and higher education sectors: development and evaluation of an integrated model. BMC Health Serv Res 2012; 12(1): 287.

22. Golenko X, Pager S, Holden L. A thematic analysis of the role of the organisation in building allied health research capacity: a senior managers' perspective. BMC Health Serv Res 2012; 12(1): 276.

23. Marshall AP, Roberts S, Baker MJ, Keijzers G, Young $J$, Stapelberg NC, et al. Survey of research activity among multidisciplinary health professionals. Aust Health Rev 2016; 40(6): 667-73.

24. Misso ML, llic D, Haines TP, Hutchinson AM, East CE, Teede HJ. Development, implementation and evaluation of a clinical research engagement and leadership capacity building program in a large Australian health care service. BMC Med Educ 2016; 16(1): 13.

25. Slade SC, Philip K, Morris ME. Frameworks for embedding a research culture in allied health practice: a rapid review. Health Res Policy Syst 2018; 16(1): 29 .

26. Matus J, Walker A, Mickan S. Research capacity building frameworks for allied health professionals: a systematic review. BMC Health Serv Res 2018; 18(1): 716.

27. Wenke RJ, Thomas R, Hughes I, Mickan S. The effectiveness and feasibility of TREAT (Tailoring Research Evidence and Theory) journal clubs in allied health: a randomised controlled trial. BMC Med Educ 2018; 18(1): 104.

28. Mickan S, Wenke R, Weir K, Bialocerkowski A, Noble C. Strategies for research engagement of clinicians in allied health (STRETCH): a mixed methods research protocol. BMJ Open 2017; 7: e014876.

29. Rogers EM. Diffusion of innovations. 4th ed. New York: Simon \& Schuster Inc; 1995.

30. Michie S, van Stralen MM, West R. The behaviour change wheel: a new method for characterising and designing behaviour change interventions. Implement Sci $2011 ; 6(1): 42$.

31. Del Mar C, Askew D. Building family/general practice research capacity. Ann Fam Med 2004; 2(suppl 2): s35-s40.

32. Farmer E, Weston K. A conceptual model for capacity building in Australian primary health care research. Aust Fam Physician 2002; 31 (12): 1139-42. [Do not delete section break]

assitis rem volendae nulparc hictio il maio. Ebisqua tesent. 


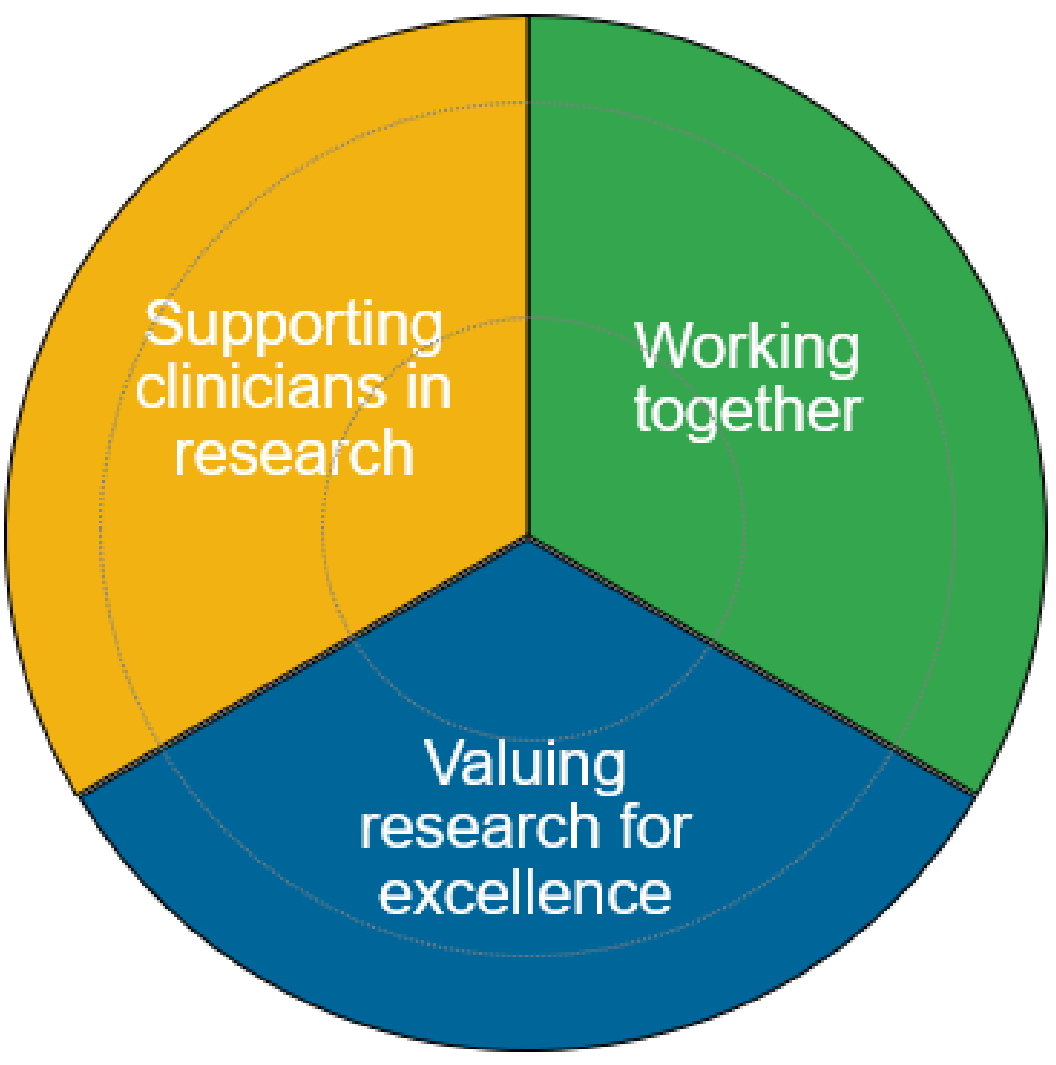

\begin{tabular}{|c|c|c|c|}
\hline & $\begin{array}{l}\text { Supporting } \\
\text { clinicians in research }\end{array}$ & Working together & $\begin{array}{l}\text { Valuing research } \\
\text { for excellence }\end{array}$ \\
\hline $\begin{array}{l}\text { Sub- } \\
\text { components }\end{array}$ & $\begin{array}{l}\text { - Opportunities to get involved } \\
\text { - Research friendly workplace } \\
\text { - Mentoring/supervision } \\
\text { - Skill mix of teams } \\
\text { - Education and training } \\
\text { - Post-graduate study } \\
\text { - Protected time and funding } \\
\text { - Reward and recognition } \\
\text { - Access to resources }\end{array}$ & $\begin{array}{l}\text { - Collaborations and } \\
\text { partnerships } \\
\text { - Shared purpose and drivers } \\
\text { - Coordinated approach } \\
\text { including team projects } \\
\text { - Shared expertise }\end{array}$ & $\begin{array}{l}\text { - Visible support for research } \\
\text { - Research as core business } \\
\text { - Prioritise research that is } \\
\text { 'close to practice' } \\
\text { - Integrate local research } \\
\text { findings back into practice }\end{array}$ \\
\hline
\end{tabular}




\section{Supporting clinicians in research:}

\section{Opportunities to get involved:}

- Encourage and provide opportunities for all practitioners to get involved in doing research. $[1,2,5,6]$

- Support practitioners to participate in different ways, depending on the service needs and individuals' interests, motivation and available time. $[1,2,6,7]$

Examples of research participation include: $[2,8]$

- identifying research ideas based on problems, gaps and issues in practice

- helping design feasible, practical and cost-effective methodologies

- collecting and/or analysing data

- helping write research reports and manuscripts for publications

- Give individual practitioners the opportunity to engage in small research projects. [1,6]

- $\quad$ Use journal club to help support research projects by critically appraising relevant literature. [1]

\section{Research friendly workplace:}

- Accommodate and value individuals' different research interests, motivations, abilities, time commitments and career paths. [1]

- Consult staff members about what they think is needed to build research capacity. [4]

- Promote the everyday application of critical thinking skills and evidence-based practice, as these skills are foundational to doing research. [2]

- Prioritise supporting and strengthening the research abilities and interests of those practitioners who are most interested and motivated to participate in research. $[7,9,10]$

- Be flexible in supporting flexible work arrangements for research. [10,18]

- Support secondment opportunities as a means of building research skills. [2]

- $\quad$ Support staff with joint clinical and academic appointments. [16]

\section{Protected time and funding:}

- Quarantine time for research within work hours [7,10,11,12], e.g. one day/week per team or department. [13]

- $\quad$ Protect funding for clinical backfill arrangements. [2,4,5,10]

- Develop systems that allow practitioners to take time off-line to do research. [5]

- $\quad$ Provide access to some in-kind [internal] funding. [5,15]

- Assist practitioners to identify and apply for research funding. [6,18]

- $\quad$ Make use of local funding opportunities. [2]

- Optimise access to information about upcoming funding opportunities. [2]

- Strategically make use of supernumery resources [e.g. students] to assist with either doing research (i.e. honours students) or to support clinical backfill. [1]

- Collaborate with academics and research fellows/facilitators/officers to help secure funding. [5,6]

- Pool funds to employ a research assistant who can assist practitioners to conduct research. [4] 


\section{Mentoring:}

- $\quad$ Seek out mentoring/supervision from more experienced researchers. [1,2,4,5,6,7,10,11,12,13,14,18]

- Identify potential research mentors, role models and champions in your team. [5]

- Match novice researchers with more experienced researchers. [2]

- $\quad$ Seek opportunities for mentoring in individual or group formats. [2,4]

- Develop structures/processes for research mentoring e.g. regular meetings, [1] formal agreements. [2,6]

- $\quad$ Support sustained engagement with mentoring relationships over time. [2,6,18]

\section{Skill mix of teams:}

- Consider research skill mix of teams when planning staffing. [2]

- Make the most of existing research capacity within the team/service [2], e.g.

- engage those practitioners who already have some skills to help more novice researchers.

\section{Education \& training:}

- Undertake research training needs assessments. [2]

- Seek out education and training that is appropriate to the needs, interests, existing skills and backgrounds of individuals and teams. $[2,5,6,7,11,12,13]$

- Engage with university partners to access additional research education and training. [1,5,6]

- Optimise access to information about upcoming education and training opportunities. [2,4], e.g. by developing or using an existing local website/intranet page to disseminate information. [1]

- Develop a directory of local research resources and supports. [2]

- Support practitioners to undertake research higher degrees or other formal post-graduate study to build their research skills. [1,6,7]

- Increase incentives for practitioners to acquire research qualifications. [5]

\section{Reward and recognition:}

- Identify and reinforce intrinsic rewards for research (e.g. skill development, personal satisfaction from succeeding at a challenging task). [4]

- Provide extrinsic rewards and incentives for research achievements (e.g. financial incentives, recognition, greater professional/career opportunities including secondments). [2,5]

- $\quad$ Support research career opportunities including access to research career pathways. [2,3,5]

- Organise local team events for practitioners to present their research. $[4,10,16]$

- Encourage and support practitioners to attend external conferences. [4,18]

\section{Access to resources:}

- Provide access to infrastructure and resources such as library, software, desk and computer use. [5,13]

- Engage with university partners to access additional infrastructure and resources (e.g. libraries and software). [5] 


\section{Collaborations and partnerships:}

- Build and maintain strategic research collaborations/partnerships/networks/linkages to exchange ideas, knowledge, skills and expertise, share resources and work on projects together $[1,2,3,4,5,6]$, and build a 'critical mass' of research-active staff. [5]

- Collaborate/partner with:

- Colleagues in your own team $[1,2,4]$

- Other professional groups $[2,3,6,16]$

- Other teams, services and organisation $[1,2,3,4,5]$

- Universities $[1,2,5,6,7,14]$

- Industry [1]

- Develop partnerships with academics and students (co-supervise honours students). [1,2,5,6,7,14]

- Integrate practice-driven questions with the perspectives and skill base of academic partners. $[1,6]$

- Establish conjoint/collaborative academic-practitioner positions. [1,2,5]

- $\quad$ Focus on building and maintaining partnerships over time. [2]

\section{Shared purpose:}

- Identify the strategic research drivers for your team/service and for potential partners. [1]

- Link up with partners who are geographically close and have common local drivers. [1]

- Organise networking events to discuss and develop research ideas. [1]

- Develop a shared vision and common values to underpin partnerships. [1]

- Co-ordinate research priorities with those of universities and other organisations. [1]

- Get equal commitment from all partners. [1]

- Specify proposed outcomes and impacts of collaborative projects early on, and link these to the strategic aims of the partner organisation/s. [1]

- Commit time to the early stages of developing collaborative projects. [1]

- Jointly implement research projects and evaluate outcomes. [6]

- Share ownership/authorship of research. [1]

- Develop partnerships through co-funded research projects. [5]

\section{Team-based approach:}

- Coordinate team-based projects as well as individual research projects. $[1,2,5,6,10,13]$

- Managers to lead/facilitate team-based projects. [2,7]

- Create a research register of current and potential research questions and project ideas. [16] 


\section{Shared expertise:}

- Share research knowledge and skills with others in your team and wider networks. [2]

Match up novice and experienced researchers. [2]

- Share research interests and findings of previous research projects. [4]

\section{Valuing research for excellence:}

\section{Visible support for research:}

- Managers to demonstrate visible/tangible support and endorsement of research, [1,2,4,5,15,17] e.g. developing structured processes and systems for research. [1,5]

\section{Research as core business:}

- Value and prioritise research as part of core business, as reflected in the team's mission, vision and strategic planning. [5]

- $\quad$ Add research as a regular agenda item for discussion in team meetings. $[3,4,16]$

- Conduct team-based research strategy/planning meetings. [1,3]

- $\quad$ Encourage and expect staff to participate in research. [2,4]

- Get leaders/managers actively involved in research. [2]

- Legitimise a range of research activities as being part of usual practice, including audits, action research and participatory enquiry. $[1,2]$

- Keep research issues a factor in daily practice planning. [4]

- Reward staff who engage in, lead, and facilitate research. [17]

- Include research in Role Descriptions, especially for senior staff. [2,4,5,7]

- Include research in Role Descriptions for new positions/future recruitment - to attract research interested/active applicants. [7]

- Include research in PAD/PDP, annual performance appraisals. [2]

\section{Prioritise research that is 'close to practice':}

- Prioritise research projects which address local service issues and needs, and which will directly inform clinical decision-making in practice. $[1,2,3]$

Identify strategic drivers for research within the team/service. [1]

- Systematically solicit and develop research questions and ideas that arise directly from practice. [1]

- Capitalise on dissatisfaction with the "status quo" of service delivery. [4]

- $\quad$ Link outcomes of research projects to the strategic aims of the team. [1]

- Help design and implement projects which use patient-centred outcome measures and realistic methodologies that are feasible in practice. [2] 


\section{Integrate local research findings back into practice:}

- Apply locally developed research knowledge to inform clinical practice and local strategy policy. [2,6]

- Encourage action research and participatory inquiry involving cycles of action, reflection and dissemination of research findings into practice. [2]

- Create opportunities and encourage practitioners to disseminate research findings widely

[e.g. journal article publications, conference presentations, local reporting, fact sheets, media], so that they can have an impact on practice both locally and beyond. [2,4,6]

\section{References:}

1. Whitworth A, Haining S, Stringer H. Enhancing research capacity across healthcare and higher education sectors: development and evaluation of an integrated model. BMC Health Serv Res 2012; 12[1]: 287.

2. Cooke J. A framework to evaluate research capacity building in health care. BMC Fam Pract 2005; 6[44]: 1-11.

3. Hulcombe J, Sturgess J, Souvlis T, Fitzgerald C. An approach to building research capacity for health practitioners in a public health environment: an organisational perspective. Aust Health Rev 2014; 38[3]: 252-8.

4. Bamberg J, Perlesz A, McKenzie P, Read S. Utilising implementation science in building research and evaluation capacity in community health. Aust J Prim Health 2010; 16[4]: 276-83.

5. Golenko X, Pager S, Holden L. A thematic analysis of the role of the organisation in building allied health research capacity: a senior managers' perspective. BMC Health Serv Res 2012; 12[1]: 276.

6. Joubert L, Hocking A. Academic practitioner partnerships: a model for collaborative practice research in social work. Australian Social Work 2015; 68[3]: 352-63.

7. Pager S, Holden L, Golenko X. Motivators, enablers, and barriers to building allied health research capacity. J Multidiscip Healthc 2012 ;5: $53-9$.

8. Misso ML, Ilic D, Haines TP, Hutchinson AM, East CE, Teede HJ. Development, implementation and evaluation of a clinical research engagement and leadership capacity building program in a large Australian health care service. BMC Med Educ 2016; $16[1]: 13$.

9. Borkowski D, McKinstry C, Cotchett M, Williams C, Haines T. Research culture in allied health: a systematic review. Aust J Prim Health 2016; 22[4]: 294-303.

10. Harvey D, Plummer D, Nielsen I, Adams R, Pain T. Becoming a clinician researcher in allied health. Aust Health Rev 2016; 40[5]: 562-9.

11. Alison JA, Zafiropoulos B, Heard R. Key factors influencing allied health research capacity in a large Australian metropolitan health district. J Multidiscip Healthc 2017; 10: 277-91.

12. Harding KE, Stephens D, Taylor NF, Chu E, Wilby A. Development and evaluation of an allied health research training scheme. $J$ Allied Health 2010; 39[4]: 143-8.

13. Holden L, Pager S, Golenko X, Ware RS, Weare R. Evaluating a team-based approach to research capacity building using a matched-pairs study design. BMC Fam Pract 2012; 13[1]: 16.

14. Marshall AP, Roberts S, Baker MJ, Keijzers G, Young J, Stapelberg NC, et al. Survey of research activity among multidisciplinary health professionals. Aust Health Rev 2016; 40[6]: 667-73.

15. Pickstone C, Nancarrow S, Cooke J, Vernon W, Mountain G, Boyce R. Building research capacity in the allied health professions. Evid Policy 2008; 4[1]: 53-68.

16. Skinner EH, Williams CM, Haines TP. Embedding research culture and productivity in hospital physiotherapy departments: challenges and opportunities. Aust Health Rev 2015; 39[3]: 312-4.

17. Cooke J, Nancarrow S, Dyas J, Williams M. An evaluation of the 'designated research team' approach to building research capacity in primary care. BMC Fam Pract 2008; 9: 37.

18. Ried K, Farmer EA, Weston KM. Bursaries, writing grants and fellowships: a strategy to develop research capacity in primary health care. BMC Fam Pract 2007; 8[1]: 19. 